\section{Nondestructive Methods to Estimate Leaf Area in Vitis vinifera $\mathrm{L}$.}

\author{
F.J. Montero, J.A. de Juan, A. Cuesta, and A. Brasa \\ Departamento de Producción Vegetal y Tecnología Agraria, Escuela Técnica \\ Superior de Ingenieros Agrónomos, Universidad de Castilla-La Mancha, \\ Campus Universitario s/n, 02071-Albacete, Spain
}

Additional index words. vine, leaf area, image processing, models, length-width method, grape

\begin{abstract}
The importance of rapid, nondestructive, and accurate measurements of leaf area (LA) in agronomic and physiological studies is well known, but a search of the literature revealed little information available for grape (Vitis vinifera $\mathbf{L}$.). The results described herein include a comparison of 12 different mathematical models for estimating leaf area in 'Cencibel'. The simplest, most accurate regression equations were: $L A_{i}=0.587$ $\mathrm{LW}\left(R^{2}=0.987\right)$ and $L A_{i}=0.588 \mathrm{LW}\left(R^{2}=0.994\right)$, where $L A_{i}$ is leaf area measured using image analysis and $L W$ is leaf length $\times$ maximum width. Use of maximum width $(W)$, leaf length $(L)$, petiole length $\left(L_{p}\right)$, and dry weight of leaves (DML) as single variables in the regression equations were not as closely associated with total leaf area, although their $R^{2}$ values were also highly significant.
\end{abstract}

The importance of vineyards in semiarid regions is recognized worldwide for their social, economic and environmental effects. Europe contains $57 \%$ of the world surface area of vineyards, and $53 \%$ of the total world production (Food and Agriculture Organization, 1993). Spain (1,250,000 ha in 1994), France (950,000 ha) and Italy (940,000 ha), are the main producing countries.

To describe the characteristics of vine canopies, leaf area index (LAI) is one of the most commonly used parameters, along with leaf distribution and level of radiation interception. Leaf area (LA) is associated with many agronomic and ecological processes, including photosynthesis, transpiration, and energy balance (Gardner et al., 1990). Plant physiologists and agronomists have demonstrated the importance of this parameter in estimating crop growth, developmental rate, and yield potential (Gallagher and Biscoe, 1978). The biomass produced by a plant is more closely associated with the total size of its assimilative system than with the photosynthetic rate of single leaves (Watson, 1952).

The accurate determination of LA is a key issue in crop growth analysis (Hunt, 1982), as simple regression models relating LA and crop growth rate are commonly used to estimate crop yield (Aase, 1978; Knisel, 1980). The importance of LAI as a surface state

Received for publication 20 July 1999. Accepted for publication 11 Nov. 1999. This work was partly funded by the Commission of the European Communities through the EFEDA Project (contract EV5V-CT93-0272). The support given by the Regional Government of Castilla-La Mancha through the Experimental Research Vine Centre in Tomelloso, is most gratefully acknowledged.The cost of publishing this paper was defrayed in part by the payment of page charges. Under postal regulations, this paper therefore must be hereby marked advertisement solely to indicate this fact. variable is seen in its widespread applications, ranging from modeling biomass productivity (McLeon and Running, 1988) to studying radiative transfer (Lang and Kiang, 1986; Norman and Campbell, 1989). With increasing emphasis on the use of remote sensing data to characterize the underlying canopy, LAI will increase in importance in climatological research (Spanner et al., 1990).

LA has been estimated by many different methods. Marshall (1968) classified these methods into two broad classes: 1) destructive and nondestructive, and 2) direct and indirect. The simplest method is based on drawing leaf contours on a paper, and determining LA by measuring the area of the paper with a planimeter or by weighing it. Other methods use optical or photoelectrical instruments, air currents, or hydraulic planimeters. Kvet and Marshall (1971) concluded that the best method is dependent on how much plant material can be measured, the accuracy required and the time and personnel available. Today methods based on photoelectrical instruments are the most common, although destructive methods are also used.

A number of simple methods are currently being used to estimate LA (Gamiely et al., 1991; Payne et al., 1991; Robbins and Pharr, 1987) including: 1) linear measurements of leaf length (L);2) maximum width (W);3) petiole length $\left.\left(\mathrm{L}_{\mathrm{p}}\right) ; 4\right)$ leaf length $\times$ maximum width $(\mathrm{LW}) ; 5)$ the square of the length $\left(\mathrm{L}^{2}\right) ; 6$ ) the square of the width $\left(\mathrm{W}^{2}\right)$; or 7$)$ some combination of these variables (Robbins and Pharr, 1987). Kemp (1960) and Marshall (1968) indicated that these methods are popular because they are simple, nondestructive, and donot require expensive instruments; however, measurement of large plants is timeconsuming.

Another accurate technique often utilized is the ratio of LA : leaf weight (LW) (Palaniswamy and Gómez, 1974). Values vary depending on phenological stage, cultivar, plant age, density, and the amount of irrigation received (Epstein and Robinson, 1965; Hoffman, 1971; McKee, 1964; Palit and Bhattacharyya, 1984).

In some studies, LW has been used to estimate LA. Both dry and fresh weight (Winter et al., 1956) appear highly related to LA (Aase, 1978; Payne et al., 1991), but this relationship is not always consistent (Palit and Battacharyya, 1984), varying with the state of development and environmental conditions (Blackman, 1956).

While mathematical models have been widely used to estimate LA in many arable crops, little modeling has been done in Vitis vinifera. Manivel and Weaver (1974) found a high correlation between the length of vine leaves and their area $\left(R^{2}=0.91\right)$. Carbonneau (1976) and Carbonneau and Mabrouck (1996) proposed a method using a number of linear parameters to estimate LA. The best results were obtained by adding the lengths of the two main lateral veins. The coefficient of determination was $\approx 0.95$ when $30 \%$ of the leaves on one stem were measured.

The objectives of this research were to: 1) design and evaluate a number of regression models to estimate vine LA by nondestructive methods; 2) determine whether leaf weight can be used to estimate LA; and 3) evaluate computer-aided methods in morphological and morphometric studies of vine leaves. All measurements were made on a single cultivar, 'Cencibel'.

\section{Materials and Methods}

Data were collected during 1995 and 1996 at a rainfed cropping farm at Tomelloso (lat. $39^{\circ} 10^{\prime} \mathrm{N}$, long. $\left.3^{\circ} 1^{\prime} \mathrm{W}\right)$, Castilla-La Mancha, on the central plateau of Spain, in an almost flat plain with altitudes $\approx 700 \mathrm{~m}$. The climate is temperate Mediterranean, with sudden changes from cold to warm months, and high daily oscillations in maximum and minimum temperatures. Spring frosts are very unusual. The soils are Calcixerollic-Petrocalcic Xerochrepts and are sandy-loam textured, showing a calcareous crust layer, $20 \mathrm{~cm}$ thick, $40-50 \mathrm{~cm}$ below the surface, which is the main limitation for vine roots. Average annual rainfall is $\approx 360$ $400 \mathrm{~mm}$, making Castilla-La Mancha one of the driest regions in Europe. During the study, 1996 was a typical year, but there was a late frost in March, and an unusually dry period from May to October in 1995.

The study was conducted in a $2.5-\mathrm{m}$ square plantation, in the middle of a 3-ha area of highyielding (2500-3500 kg.ha $\left.{ }^{-1}\right)$ 'Cencibel' vines (Rodríguez de la Rubia, 1996). The rootstock was $41 \mathrm{~B}$, known to have high resistance to active limestone.

Leaves were collected from four plants selected at random every $10 \mathrm{~d}$ during the growing season. Measurements were begun in 1995, when the vines were at the H phenological stage (inflorescences were well developed and single flowers separated) (Baillod and Baggiolini, 1993), and continued until harvest. In 1996, sampling was begun at the J 

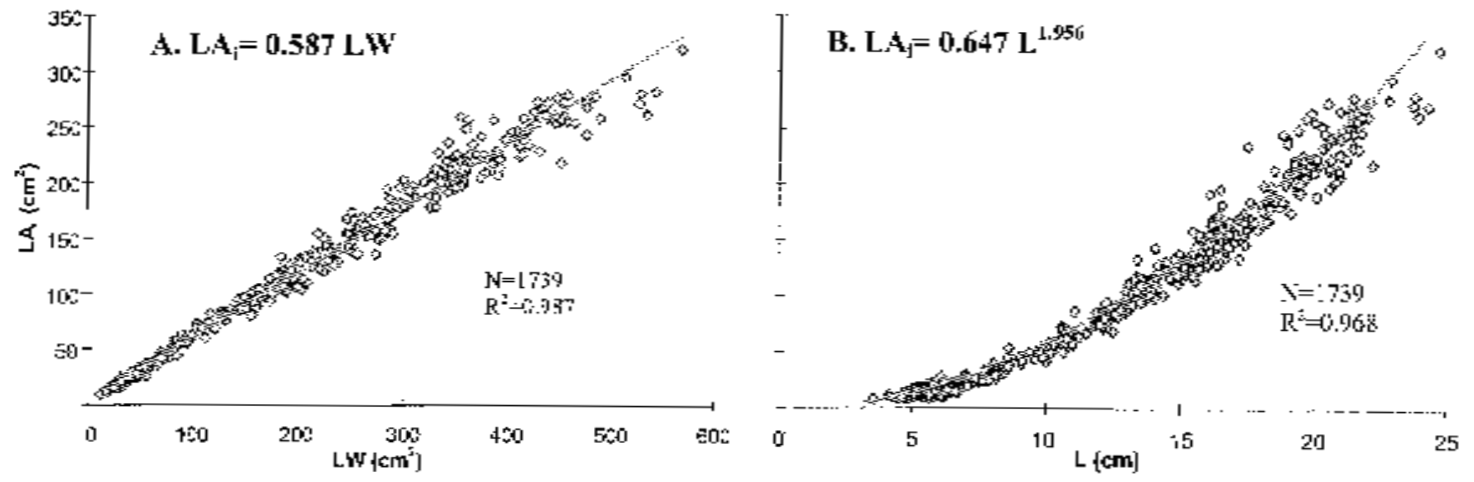

Fig. 1. The relationship of (A) $\mathrm{LA}_{i}$ estimates derived from Eq. [5] with measurements of grape leaf length (L) and width (W), and (B) LA $A_{i}$ estimates derived from Eq. [1] with mesurements of grape leaf length (L).

stage (when the young berries were enlarging) and continued until harvest.

During 1995, stems of each plant were classified according to their origin and position within the plant: 1) shoots originating from dormant buds; 2) forward shoots originating from the first fruit buds; and 3) backward shoots also emerging from the second fruit buds. In 1995 and 1996, LA was determined using an automatic analyzer (model 3100; LI-COR, Lincoln, Nebr.). The leaf length was measured from the upper edge of the leaf to the lowest point (but not to the petiole insertion as in other studies). The width was measured at the widest point perpendicular to the longitudinal axis of the leaf. The petiole length was also measured. Leaf dry weight was recorded after drying to constant weight at $80{ }^{\circ} \mathrm{C}$.

Linear and LA measurements were also made both years using an EPSON GT-8000 scanner (Seiko Epson Corp., Nagano, Japan). The following parameters were evaluated: leaf area $\left(\mathrm{LA}_{\mathrm{i}}\right)$, maximum leaf width $\left(\mathrm{W}_{\mathrm{i}}\right)$, maximum leaf length $\left(\mathrm{L}_{\mathrm{i}}\right)$, leaf perimeter $(\mathrm{P})$, and roundness index $(\mathrm{RI})\left(=4 \pi \mathrm{LA} / \mathrm{P}^{2}\right)$. Images were downloaded and processed on an IBM $512 \mathrm{~K}$ computer. The image processing software used was GLOBAL LAB Image version 2.10 (Data Translation, Marlboro, Mass.).

Correlation coefficients were calculated between all the parameters measured. An extensive range of mathematical models was tested to forecast LA, incorporating all the independent variables $\left(\mathrm{L}, \mathrm{L}^{2}, \mathrm{~W}, \mathrm{~W}^{2}, \mathrm{LW}, \mathrm{L}_{\mathrm{p}}\right.$, DML) individually or in combination. The least squared method was utilized to develop the models. Statistics were analyzed using Statgraphics version 5.0 (Statistical Graphics Corp., 1991).

\section{Results and Discussion}

All the individual measurement traits except for specific leaf area (SLA) were significantly correlated (data not shown). The measurements made on the different types of shoots did not differ significantly.

The correlation coefficient between LA calculated using the LI-COR 3100 and LA determined by image processing was very $\operatorname{high}(r>0.99)$. Nevertheless, the value obtained by image processing was selected because of its lower possibility of human error. Image processing was superior to the other methods in several ways: 1) more samples could be analyzed; 2) the experimental error was reduced; 3) subjectivity was minimized; 4) time of sampling was reduced; 5) visual information could be permanently filed; and 6) once leaves were scanned, the detailed analysis could be performed later.

Twelve mathematical equations were used to estimate LA:

$$
\begin{aligned}
& L A_{i}=a L^{b} \\
& L A_{i}=a+b L+c L^{2} \\
& L A_{i}=a+b W+c W^{2} \\
& L A_{i}=a+b W^{2} \\
& L A_{i}=a L W \\
& L A_{i}=a(L W)^{b} \\
& L A_{i}=a D M L
\end{aligned}
$$

$$
\begin{aligned}
& L A_{i}=a(D M L)^{b} \\
& L A_{i}=a+b D M L+c D M L^{2} \\
& L A_{i}=a+b L_{p} \\
& L A_{i}=a+b L_{p}+c L_{p}^{2} \\
& P=a(L W)^{b}
\end{aligned}
$$

Eq. [5], which relates LA with LW, had one of the highest correlation coefficients with LA (Table 1, Fig. 1) and was preferable to other models, which are slightly more accurate but more complicated. LA could be measured accurately by just knowing coefficient $a$, and measuring length and width. The leaf factor defined as LA $\mathrm{A}_{\mathrm{i}} / \mathrm{LW}$ had a value of

\begin{tabular}{|c|c|c|c|c|c|}
\hline$\overline{\text { Equation }^{z}}$ & Year & $\mathrm{a}$ & $\mathrm{b}$ & $\mathrm{c}$ & $R^{2}$ \\
\hline \multirow{2}{*}{$\mathrm{LA}_{\mathrm{i}}=\mathrm{a} \mathrm{L}^{\mathrm{b}}$} & 1995 & 0.647 & 1.956 & --- & 0.968 \\
\hline & 1996 & 0.656 & 1.946 & --- & 0.988 \\
\hline \multirow[t]{2}{*}{$\mathrm{LA}_{\mathrm{i}}=\mathrm{a}+\mathrm{bL}+\mathrm{cL} \mathrm{L}^{2}$} & 1995 & -20.207 & 5.441 & 0.298 & 0.946 \\
\hline & 1996 & -17.114 & 3.849 & 0.401 & 0.974 \\
\hline \multirow[t]{2}{*}{$\mathrm{LA}_{\mathrm{i}}=\mathrm{a}+\mathrm{bW}+\mathrm{c} \mathrm{W}^{2}$} & 1995 & -16.283 & 3.032 & 0.483 & 0.942 \\
\hline & 1996 & -21.833 & 4.460 & 0.433 & 0.971 \\
\hline \multirow{2}{*}{$\mathrm{LA}_{\mathrm{i}}=\mathrm{a}+\mathrm{b} \mathrm{W}^{2}$} & 1995 & -1.563 & 0.609 & --- & 0.941 \\
\hline & 1996 & 3.025 & 0.602 & --- & 0.969 \\
\hline \multirow[t]{2}{*}{$\mathrm{LA}_{\mathrm{i}}=\mathrm{a} \mathrm{LW}$} & 1995 & 0.587 & --- & --- & 0.987 \\
\hline & 1996 & 0.588 & --- & --- & 0.994 \\
\hline \multirow[t]{2}{*}{$\mathrm{LA}_{\mathrm{i}}=\mathrm{a}(\mathrm{LW})^{\mathrm{b}}$} & 1995 & 0.796 & 0.944 & --- & 0.959 \\
\hline & 1996 & 0.599 & 0.997 & --- & 0.992 \\
\hline \multirow[t]{2}{*}{$\mathrm{LA}_{\mathrm{i}}=\mathrm{a}(\mathrm{DML})^{\mathrm{b}}$} & 1995 & 120.084 & 0.758 & --- & 0.921 \\
\hline & 1996 & 128.805 & 0.851 & --- & 0.980 \\
\hline \multirow[t]{2}{*}{$\mathrm{LA}_{\mathrm{i}}=\mathrm{a}+\mathrm{bDML}+\mathrm{c} \mathrm{DML}^{2}$} & 1995 & 6.371 & 134.743 & -18.786 & 0.922 \\
\hline & 1996 & 3.653 & 146.330 & -16.607 & 0.962 \\
\hline \multirow[t]{2}{*}{$\mathrm{LA}_{\mathrm{i}}=\mathrm{a}+\mathrm{b} \mathrm{L}_{\mathrm{p}}$} & 1995 & -6.093 & 21.864 & --- & 0.723 \\
\hline & 1996 & -3.204 & 23.315 & --- & 0.895 \\
\hline \multirow[t]{2}{*}{$\mathrm{LA}_{\mathrm{i}}=\mathrm{a}+\mathrm{b} \mathrm{L}_{\mathrm{p}}+\mathrm{cL}_{\mathrm{P}}^{2}$} & 1995 & -9.683 & 23.785 & -0.197 & 0.724 \\
\hline & 1996 & -15.012 & 29.549 & -0.543 & 0.899 \\
\hline \multirow{2}{*}{$\mathrm{P}=\mathrm{a}(\mathrm{LW})^{\mathrm{b}}$} & 1995 & 4.631 & 0.534 & --- & 0.897 \\
\hline & 1996 & 4.030 & 0.554 & --- & 0.962 \\
\hline
\end{tabular}
0.587 in both years, showing cultivar stability.

Among the models using only one measurement to estimate LA, Eq. [1] was the most accurate (Fig. 1). This model has the advantage of measuring only one leaf parameter, but was not as constant from year to year as Eq. [5]. Because it contains two coefficients ( $a$ and $b$ ), both of which vary from season to season. Length alone and width were also good pre-

Table 1. Coefficients of the models used to estimate grape leaf area (LA) and perimeter (P) in Castilla-La Mancha, Spain, during 1995 and 1996.

${ }^{2} \mathrm{~L}=$ leaf length; $\mathrm{W}=$ leaf width; $\mathrm{LA}_{\mathrm{i}}=$ leaf area (by image analysis); $\mathrm{LW}=$ length $\times$ width $; \mathrm{L}_{\mathrm{p}}=$ petiole length; $\mathrm{P}=$ perimeter; $\mathrm{DML}=$ leaf dry weight. 
Table 2. Change in specific leaf area (SLA) during 1996 and its use for estimating leaf area with Eq. [7] $\mathrm{LA}_{\mathrm{i}}=$ a DML. ${ }^{\mathrm{z}}$

\begin{tabular}{lcc}
\hline \hline Date & Coefficient $a$ & SLA $\left(\mathrm{m}^{2} \cdot \mathrm{kg}^{-1}\right)$ \\
\hline 03 June & 14.03 & 17.59 \\
25 June & 12.88 & 15.93 \\
02 July & 12.60 & 15.06 \\
16 July & 11.62 & 13.85 \\
30 July & 11.38 & 13.22 \\
13 Aug. & 10.69 & 11.98 \\
27 Aug. & 10.56 & 12.08 \\
12 Sept. & 11.34 & 13.65 \\
\hline
\end{tabular}

${ }^{2} \mathrm{LA}_{\mathrm{i}}=$ leaf area (by image analysis); $\mathrm{DML}=$ leaf dry matter.

dictors of total LA, although the $R^{2}$ was lower and the mean square error (MSE) was higher than with Eq. [5].

Among the models using DML, Eq. [8] is the best in combining ease and accuracy. There is a highly significant correlation between dry matter of leaves and LA, but its main disadvantage is that the leaf has to be destroyed. Using one single coefficient could result in good fit, but SLA is not constant and changes with time during the growing season (Table 2), thus requiring the calculation of coefficients for each phenological period.

The poorest associations observed in our analysis were those using petiole length as in Eqs. [10] and [11]. However, Manivel and Weaver (1974) concluded that petiole length in the cultivar Garnacha was one of the best parameters to estimate LA. We do not know why our results differ, but the number of leaves analyzed was much lower than in their study.

The leaf perimeter could be estimated accurately following Eq. [12] from two linear measurements, length and width, because of its high coefficient of determination. Indices like RI can be obtained by relating perimeter and LA. This index cover depends on plant morphology and is included in studies that characterize cultivars.

The vine parameters that we measured in 'Cencibel' should be compared with those of other cultivars (e.g., 'Airén', 'Garnacha', 'Macabeo', and 'Cabernet Sauvignon'), to determine if the same methods are as accurate. A study with such characteristics is now under way at the Dept. of Plant Production and Agricultural Technology of the Univ. of Castilla-La Mancha.

\section{Literature Cited}

Aase, J.K. 1978. Relationship between leaf area and dry matter in winter wheat. Agron. J. 70:563565.

Baillod, M. and M. Baggiolini. 1993. Les stades repères de la vigne. Rev. Suisse Viticult. Arboricult. Hort. 28:7-9.

Blackman, G.E. 1956. Influence of light and temperature on leaf growth, p. 151-167. In: F.L. Milthorpe (ed.). The growth of leaves. Butterworths, London.

Carbonneau, A. 1976. Analyse de la croissance des feuilles du sarment de vigne: Estimation de sa surface foliare par echantillonnage. Connaissance vigne vin 10:141-159.

Carbonneau, A. and H. Mabrouck. 1996. A simple method for determination of grapevine Vitis vinifera $\mathrm{L}$. leaf area. Progrès Agricole Viticole 18:392-398.

Epstein,E. and R.R. Robinson. 1965. A rapid method for determining leaf area of potato plants. Agron. J. 57:515-516.

Food and Agriculture Organization. 1993. Anuario FAO de Producción. FAO, Rome.

Gallagher, J.N. and R.V. Biscoe. 1978. Radiation, absorption, growth and yield of cereals. J. Agr. Sci. Cambridge 91:47-60.

Gamiely, S., W.M. Randle, H.A. Mills, and D.A. Smittle. 1991. A rapid and nondestructive method for estimating leaf area of onions. HortScience 26:206.

Gardner, F.P., R. Brent, and R.L. Mitchell. 1990. Physiology of crops plants. Iowa State Univ. Press, Ames.

Hoffman, G.J. 1971. Estimating leaf area from length measurements for hybrid granex onion. Agron. J. 63:948-949.

Hunt, R. 1982. Plant growth curves. The functional approach to plant growth analysis. Edward Arnold, London.

Kemp, C.P. 1960. Methods of estimating the leaf area of grasses from linear measurements. Ann. Bot. N. S. 24:491-499.

Knisel, W.G., Jr. 1980. CREAMS: A field-scale model for chemicals, runoff, and erosion from agricultural management systems. Conservation Rpt. No. 26. U.S. Dept. Agr., Washington, D.C.

Kvet, J. and J.K. Marshall. 1971. Assessment of leaf area and other assimilating surfaces, p. 517555. In: Z. Sestak, J. Catsky, and P.G. Jarvis (eds.). Plant photosynthetic production: Manual of methods. Dr. W. Junk N. V., The Hague, Netherlands.

Lang, A.R.G. and Y. Kiang. 1986. Estimation of leaf area index from transmission of direct sunlight in discontinuous canopies. Agr. For. Meteorol. 37:229-243.

Manivel, L. and R.J. Weaver. 1974. Biometrics correlations between leaf area and length measurements of 'Grenache' grape leaves. HortScience 9:27-28.

Marshall, J.K. 1968. Methods for leaf area measurement of large and small leaf samples. Photosynthetica 2:41-47.

McKee, G.W. 1964. A coefficient for computing leaf area in hybrid corn. Agron. J. 56:240-241.

McLeon, S.D. and S.W. Running. 1988. Comparing site quality indices and productivity in ponderosa pine stands of western Montana. Can. J. For. Res. 18:346-352.

Norman, J.M. and G.S. Campbell. 1989. Canopy structure, p. 301-325. In: R.W. Pearcy (ed.). Plant physiological ecology: Field methods and instrumentation. Chapman and Hall, London.

Palaniswamy, K.M. and K.A. Gómez. 1974. Lengthwidth method for estimating leaf area of rice. Agron. J. 66:430-433.

Palit, P. and A.C. Bhattacharayya. 1984. Measurement of leaf area per plant of white jute (Corchorus capsularis L.) and tossa jute $(C$. olitorius $\mathrm{L}$.) using the average specific leaf weight value. Trop. Agr. 61:59-60, 80.

Payne, W.A., C.W. Wendt, L.R. Hossner, and C.E. Gates. 1991. Estimating pearl millet leaf area and specific leaf area. Agron. J. 83:937-941.

Robbins, N.S. and D.M. Pharr. 1987. Leaf area prediction models for cucumber from linear measurements. HortScience 22:1264-1266.

Rodríguez de la Rubia,E. 1996. Situación en CastillaLaMancha, p. 27-37. In: A. Salinas, F.J. Montero, and E. Rodríguez de la Rubia (eds.). La vid y el vino en Castilla-La Mancha. Junta de Comunidades de Castilla-La Mancha, Albacete, Spain.

Spanner, M.A., L.L. Pierce, A.L. Peterson, and S.W. Running. 1990. Remote sensing of temperature coniferous forest leaf area index: The influence of canopy closure, understory vegetation and background reflectance. Intl. J. Remote Sensing 11:95-111.

Statistical Graphics Corporation. 1991. Statgraphics v. 5.0. Statistical graphics system. Users guide. STSC, Rockville, Md.

Watson, D.J. 1952. The physiological variation in yield. Adv. Agron. 4:101-145.

Winter, E.J., P.J. Salter, G. Stanhill, and J.K. Bleasdale. 1956. Some methods of measuring leaf area, p. 151-167. In: F.L. Milthorpe (ed.). The growth of leaves. Butterworths, London. 